\title{
Added Value of Modified Anderson-Wilkins Acuteness Score in Prognostication of Patients with Acute Myocardial Infarction
}

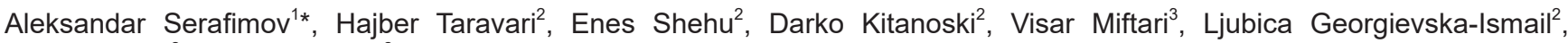 \\ Sasko Kedev², Marija Vavlukis ${ }^{2}$ \\ ${ }^{1}$ Department of Cardiology, Clinical Hospital Shtip, Faculty of Medical Sciences, University Goce Delchev, Shtip, Republic of \\ Macedonia; ${ }^{2}$ Department of Cardiology, University Clinic of Cardiology, Medical Faculty, Skopje, Republic of Macedonia; ${ }^{3}$ Department \\ of Neurology, Clinical Hospital Tetovo, Faculty of Medical Sciences, University of Tetovo, Tetovo, Republic of Macedonia
}

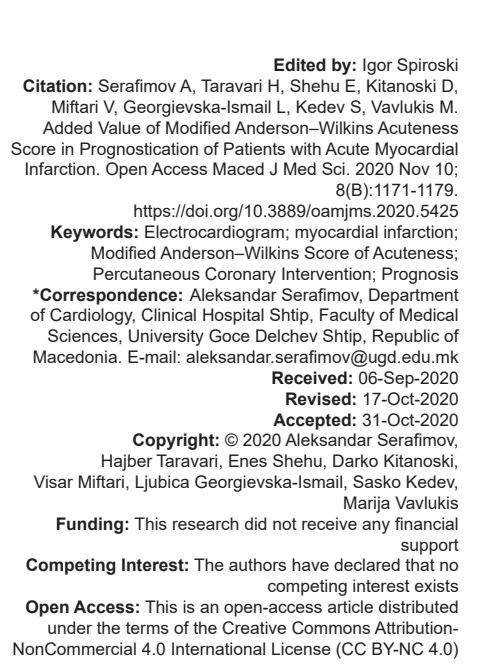

\section{Abstract}

BACKGROUND: Electrocardiogram (ECG) signs on admission can serve as a prognostic marker in patients treated for myocardial infarction (MI).

AIM: The aim of the study was to determine the predictive role of modified Anderson-Wilkins (MAW) ECG score of acuteness on the extent of myocardial injury, left ventricular (LV) remodeling, and clinical outcome in patients with acute MI.

METHODS: Prospective, observational cohort study on patients treated for MI at the University Clinic for Cardiology Subjects were analyzed for their demographic, clinical, ECG, LV functional, angiographic variables, course of treatment, and in-hospital outcome. MAW score was calculated for each patient. Patients were comparatively analyzed divided in two groups (score $<3$ and $\geq 3$ ).

RESULTS: One hundred fifty patients ( $70 \%$ males and $30 \%$ females), aged 60.9 years were included in the study. Sixty-eight patients had MAW score $<3$ (mean 1.7), and 82 had score $\geq 3$ (mean 3.5), $p>0.001$. Patients with ST-segment elevation MI had OR 2.1 ( $p>0.000$ ), and patients with multiple locations (excluding anterior) had OR 2.1 $(p>0.000)$ of having MAW score $\geq 3$. They received mechanical reperfusion $1.9(p=0.032)$ times more often. High MAW score was associated with stress hyperglycemia (OR 2.1; $p=0.032$ ); low potassium (OR 2.8; $p=0.032$ ), lower creatinine $(p=0.050)$, and higher NT-proBNP (OR 2.5; $p=0.050)$. High MAW score was associated with decreased LV function and increased LV dimensions on the follow-up echocardiography ( $p=0.050$ and 0.012 , respectively).

CONCLUSION: ECG is an important prognostic tool in MI patients. ECG-derived MAW score demonstrates a strong correlation with stress hyperglycemia, potassium, creatinine, and natriuretic peptides level and can serve as an early marker of LV remodeling after MI.

\section{Introduction}

Acute myocardial infarction (AMI) is one of the leading causes of death worldwide, with cardiovascular diseases (CVD) being responsible for $31.8 \%$ of all deaths [1]. With a longer duration of myocardial ischemia, the size of irreversibly injured and necrotic myocardium is increasing, and the extent of myocardial salvage is decreasing. Nevertheless, the speed of necrosis progression depends on the vulnerability of the myocardium to ischemia and demonstrates great variations among patients. Myocardial ischemia is related to the amount of collateral blood flow of the coronary artery and metabolic preconditioning of the myocardium [2], [3]. The progression of myocardial ischemia to myocardial necrosis translates into myocardial segmental wall motion abnormalities estimated by electrocardiography [4].

The rapid revascularization of the acutely occluded coronary artery, either with the primary percutaneous coronary intervention $(\mathrm{pPCl})$ or thrombolytic therapy, is of paramount significance for myocardial salvage, risk of subsequent heart failure, and survival [5], [6], [7]

Yet, estimation of symptom onset is very biased by sometimes inaccurate patient recollection or preexisting conditions leading to clinically "silent" myocardial ischemia. Here, we stress again the very important role of electrocardiogram (ECG) and ECG signs of acuteness and severity of the myocardial injury. The AndersonWilkins acuteness score (AW score) quantifies the acuteness of myocardial ischemia from the ECG, and according to published literature on this subject, it is superior to historical timing and treatment delay (time from symptom onset to wire) in predicting myocardial infarct size, salvage, and mortality [8], [9], [10].

The Anderson-Wilkins acuteness score evaluates the acuteness of myocardial ischemia in patients presenting with acute thrombotic occlusion of coronary artery, based on a 12-lead standard ECG. [11] Briefly, an acuteness phase is assigned based on the presence or absence of a hyperacute T-wave or an abnormal Q-wave [12]. According to the AW score, 
there are four phases, starting with the most acute one: Phase 1A: Hyperacute T-wave and no abnormal $\mathrm{Q}$-wave; phase 1B: Positive T-wave and no abnormal $\mathrm{Q}$-wave; phase 2A: Tall T-wave and abnormal $\mathrm{Q}$-wave; and phase 2B: Positive T-wave and abnormal Q-wave. The AW score ranges from 1 to 4 , with 1 being the least acute and 4 being most acute. Acute ischemia is defined as ECG acute score $\geq 3$ and non-acute ischemia as ECG acuteness score <3 [13], [14]. The AW score may indicate an electrophysiological estimate of the viability of the myocardium, independently of the patientreported symptoms onset, and may subsequently be used as a predictor of achievable myocardial salvage [11], [12], [13].

Echocardiography is the most frequently used non-invasive diagnostic technique which provides information regarding ventricular function and presence or absence of wall motion abnormalities [15]. Left ventricular ejection fraction (LVEF) and volumes are well-known predictors of prognosis in patients with AMI. Lower EF and larger volumes result in worse clinical outcomes [16]. According to authors White et al. [17] and Møller et al. [18], post-MI patients with EF <40\% and end-systolic volume $>130 \mathrm{~cm}^{3}$ have a 5-year survival rate of $65 \%$ and $52 \%$, respectively.

In this study, we aimed to determine if there is a place for modified Anderson-Wilkins (MAW) ECG score of acuteness in the prediction of the extent of myocardial injury, as measured with biochemical and echocardiography-gained parameters. Our secondary goal was to find out if this score can serve as a predictor of early in-hospital outcome in MI patients.

\section{Methods}

A longitudinal, prospective observational cohort study was undertaken on patients hospitalized at the University Clinic of Cardiology over the period of September 2018-March 2019 for acute MI. Inclusion criteria: Patients (all incomers) hospitalized for AMI over the aforementioned period who were willing to participate in the study and gave signed informed consent. Exclusion criteria: Patients who were not consented to participate in the study and patients who suffered in-hospital mortality over the index hospitalization.

Data were collected on demographics, CV risk factors, comorbidities, ECG-signs of myocardial injury, biomarkers of myocardial injury, LV function, angiographic distribution of the disease, MI treatment, and medications used and early in-hospital outcome.

At the study entry, to collect variables of interest, every patient underwent: taking medical history; physical examination; 12-lead ECG recording; blood sampling for: Hemogram, lipid (non-fasting), and glycemic profile, markers of myocardial injury: Highly sensitive troponin $\mathrm{T} / \mathrm{I}$ (hsTn) and brain natriuretic peptide (NTpro-BNP), biochemical parameters; coronary angiography and echocardiography (2-D transthoracic echocardiography [2D TTE]).

The first post-hospital evaluation was performed in the time-frame period of 3-6 months after the index event. Medical history, physical examination, 12-lead ECG, and 2D TTE were undertaken.

Stratification of patients according to the severity and acuteness of ischemia was made from the admission electrocardiogram (12-lead pre-hospital or first in-hospital ECG recording with good quality 25 $\mathrm{mm} / \mathrm{s}, 10 \mathrm{~mm} / \mathrm{mV}$, and $150 \mathrm{~Hz}$ ). For the purposes of our study, we applied the calculation of the modified Anderson-Wilkins (MAW) ECG score of acuteness, in details described by Hedén et al. [13], according to the following formula:

$$
\text { Accuteness score }=\frac{\begin{array}{c}
4(\# \text { leads } 1 \mathrm{~A})+3(\text { \#leads } 1 \mathrm{~B}) \\
+2(\# \text { leads } 2 \mathrm{~A})+1(\# \text { leads } 2 \mathrm{~B})
\end{array}}{\sum \text { \#leads with } 1 \mathrm{~A}, 1 \mathrm{~B}, 2 \mathrm{~A}, 2 \mathrm{~B}}
$$

Patients were divided in two groups: Group A: MAW ECG score of acuteness $=0(<3)$ and Group B: MAW ECG score of acuteness $=1(\geq 3)$.

The study was approved by the ethics committee of the University Clinic of Cardiology and was conducted in accordance with the Helsinki Declaration. Informed consent was obtained from all patients before their inclusion in the study.

IBM SPSS statistical software version 22 was used for statistical analysis. Descriptive and comparative statistical methods were applied. Continuous variables were presented as means, while categorical as frequencies and percentages. Comparative statistic tests: Chi-square test for variables with dichotomous distribution, t-test, and one-way ANOVA for continuous variables with two or more categories were applied. Risk ratios with a 95\% confidence interval were calculated, and the significance was determined using Cochran and Mantel-Haenszel test. Receiver operating characteristic (ROC) curves (receiver operator characteristic curves) were used for prediction capability. Correlations, uni- and multivariate linear, and logistic regression analysis were undertaken to identify significantly associated variables. Significance was determined at the level of 0.05 .

\section{Results}

Patients treated for AMI at the University Clinic of Cardiology over the period of September 2018-March 2019 , were 150 in total, with $70 \%$ males and $30 \%$ females, at mean age of 61 years were subjected to analysis. 
No statistically significant differences were observed in age and gender distribution (Figure 1) and CV risk profile, except for hyperlipidemia and arterial hypertension being more frequent in patients with MAW score $<3$ (OR 1.5 and 1.6, $p=0.038$ and $p=n s$, respectively) (Table 1 ).

From $150 \mathrm{Ml}$ patients, $71.3 \%$ had STEMI and an OR of 2.1 ( $p>0.000)$, having MWA score $\geq 3$. A statistically significant difference for MAW score was observed in patients according to the Ml location. In patients with anterior Mls, there was an equal distribution of MAW score, while MAW score $<3$ predominated in patients with inferior Mls, and score $\geq 3$ predominated in patients with multiple locations excluding anterior $\mathrm{MI}, \mathrm{OR}$ $2.1(p=0.016)$. Furthermore, Group B patients had bigger ST-segment elevation $(p>0.000)$, while no difference was observed with respect to the transmural distribution of $\mathrm{MI}$ (as expressed through the presence of $Q$ sequela). No significant differences in the MAW score were observed with respect to the extent and severity of the disease, as assessed angiographically (Table 1).

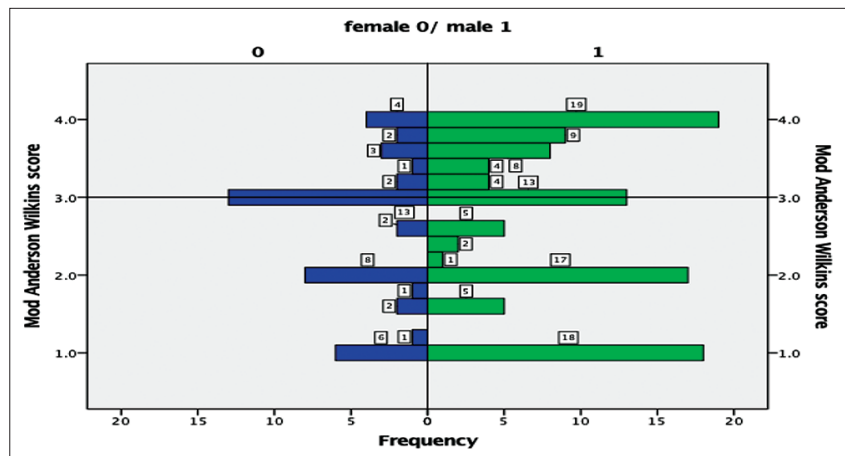

Figure 1: Population plot - distribution of MAW score across genders, with horizontal reference line set at value of 3

Table 1: Clinical characteristics of the study group and in the two comparator groups

\begin{tabular}{|c|c|c|c|c|c|}
\hline Variable & $\begin{array}{l}\text { Total } \\
\text { (No./\%) }\end{array}$ & $\begin{array}{l}\text { Group A } \\
(\text { Score <3)\% }\end{array}$ & $\begin{array}{l}\text { Group B } \\
\text { (Score } \geq 3) \%\end{array}$ & Sig. & $\begin{array}{l}\text { OR (for } \\
\text { categorical } \\
\text { variables) } \\
(95 \% \mathrm{Cl})\end{array}$ \\
\hline Gender & $150(100)$ & $68(45.3)$ & $82(54.7)$ & & \\
\hline Female & $45(30)$ & $20(44.4)$ & $25(55.6)$ & ns & \\
\hline Male & $105(70)$ & $48(45.7)$ & $57(54.3)$ & & \\
\hline Age (years) & $60.9 \pm 11.9$ & $60.8 \pm 11.9$ & $61.0 \pm 12.0$ & ns & \\
\hline BMI $(\mathrm{kg} / \mathrm{m})$ & $28.4 \pm 4.9$ & $28.8 \pm 4.1$ & $28.2 \pm 5.3$ & ns & \\
\hline $\mathrm{BSA}\left(\mathrm{kg} / 1 \mathrm{~m}^{2}\right)$ & $1.9 \pm 0.2$ & $1.9 \pm 0.1$ & $1.9 \pm 0.2$ & ns & \\
\hline Obesity (BMI >30) & $20(13.3)$ & $6(8.8)$ & $14(17.1)$ & ns & \\
\hline HLP & $137(91.3)$ & $66(97.4)$ & $71(86.6)$ & $0.021^{*}$ & $\begin{array}{l}1.6(1.2-2.2) \\
0.038\end{array}$ \\
\hline Family history & $87(58)$ & $40(58.8)$ & $47(57.3)$ & ns & \\
\hline Smoking & $98(65.2)$ & $42(61.8)$ & $56(68.3)$ & ns & \\
\hline HTA & $133(88.7)$ & 64 (94.1) & $69(84.1)$ & $0.046^{*}$ & 1.5 (1.0-2.0); ns \\
\hline DM & $44(29.3)$ & $19(27.9)$ & $25(30.5)$ & ns & \\
\hline Previous MI & $21(14)$ & $11(16.2)$ & $10(12.2)$ & ns & \\
\hline Previous $\mathrm{PCl}$ & $20(13.3)$ & $10(14.7)$ & $10(12.2)$ & ns & \\
\hline Preexisting EF $<50 \%$ & $8(5.3)$ & $4(5.9)$ & $4(4.9)$ & ns & \\
\hline COPD & $18(5.3)$ & $6(8.8)$ & $12(14.6)$ & ns & \\
\hline Anemia & $11(7.3)$ & $6(8.8)$ & $5(6.1)$ & ns & \\
\hline GIT disease & $10(6.7)$ & $5(7.4)$ & $5(6.1)$ & ns & \\
\hline
\end{tabular}

However, there were significant differences

in MAW score and therapeutic treatment approach. Patients with MAW score $\geq 3$ had OR of $1.9(p=0.033)$ for receiving primary $\mathrm{PCl}(\mathrm{pPCl})$ treatment as compared to patients from Group A. Furthermore, patients from Group B more frequently received revascularization on more than one "culprit" coronary artery $(p=0.003)$. As for medical therapy, patients from Group B had OR of 1.5 and 1.4 ( $p=$ ns for both) to receive mineralocorticoid receptor antagonists and loop diuretics. No significant differences for in-hospital morbidity or mortality were observed, although they were statistically insignificantly higher in Group B patients (Table 1).

Surprisingly, no significant differences were found for LV function between the groups, not only on the first in-hospital echocardiography but also on the 3-6month follow-up test (after the period of LV remodeling). In the patients from Group B, statistically significant thinner IVS was observed (0.009), which can be discussed accompanied with $Q$-wave sign of transmural MI that was more frequent in the same patients (Table 2).

Table 2: LV morphologic and functional variables as measured by 2-D TTE of the study group and in the two comparator groups on the first and second study

\begin{tabular}{|c|c|c|c|c|}
\hline Variable & $\begin{array}{l}\text { Total } \\
\text { (No./\%) }\end{array}$ & $\begin{array}{l}\text { Group A } \\
(\text { Score }<3) \%\end{array}$ & $\begin{array}{l}\text { Group B } \\
(\text { Score } \geq 3) \%\end{array}$ & Sig. \\
\hline \multicolumn{5}{|l|}{ First measurement } \\
\hline LVEDd (mm) & $51.8 \pm 5.1$ & $52.1 \pm 5.2$ & $51.6 \pm 5.0$ & ns \\
\hline LVESd $(\mathrm{mm})$ & $36.5 \pm 5.7$ & $36.5 \pm 5.7$ & $36.5 \pm 5.7$ & $\mathrm{~ns}$ \\
\hline $\mathrm{EF}(\%)$ & $52.4 \pm 9.6$ & $52.7 \pm 9.1$ & $52.2 \pm 10.1$ & ns \\
\hline $\mathrm{LA}(\mathrm{mm})$ & $38.2 \pm 4.4$ & $38.6 \pm 3.8$ & $37.8 \pm 4.8$ & ns \\
\hline IVS (mm) & $11.5 \pm 1.7$ & $11.9 \pm 1.6$ & $11.2 \pm 1.8$ & 0.009 \\
\hline Diastolic dysfunction & $59(40.4)$ & $26(39.4)$ & $33(41.3)$ & ns \\
\hline \multicolumn{5}{|l|}{ LV dysfunction } \\
\hline $\mathrm{EF}<50 \%$ & $70(46.7)$ & $32(47.8)$ & $38(47.5)$ & ns \\
\hline$E F>50 \%$ & 77 (51.3) & $35(52.2)$ & $42(52.5)$ & \\
\hline \multicolumn{5}{|l|}{ Second measurement } \\
\hline LVEDd (mm) & $53.5 \pm 5.1$ & $53.1 \pm 5.6$ & $53.7 \pm 4.9$ & ns \\
\hline LVESd (mm) & $38.4 \pm 5.2$ & $37.9 \pm 5.2$ & $38.7 \pm 5.3$ & ns \\
\hline $\mathrm{EF}(\%)$ & $50.6 \pm 8.4$ & $51.5 \pm 7.7$ & $50.1 \pm 8.9$ & ns \\
\hline $\mathrm{LA}(\mathrm{mm})$ & $39.3 \pm 3.9$ & $39.6 \pm 4.0$ & $39.2 \pm 3.9$ & ns \\
\hline IVS (mm) & $11.0 \pm 2.2$ & $10.9 \pm 2.6$ & $11.1 \pm 2.0$ & ns \\
\hline Diastolic dysfunction & $29(70.7)$ & $11(78.6)$ & $18(66.7)$ & ns \\
\hline \multicolumn{5}{|l|}{ LV dysfunction } \\
\hline $\mathrm{EF}<50 \%$ & $24(37.5)$ & $9(37.5)$ & $15(37.5)$ & ns \\
\hline$E F>50 \%$ & 77 (62.5) & $15(62.5)$ & $25(62.5)$ & \\
\hline
\end{tabular}
LVEDs: Left ventricular end-systolic dimension, EF: Ejection fraction, LA: Left atrium; IVS: Interventricula septum

We performed a paired samples analysis for each patient on the first and second echocardiography study, and also after dividing the patients according to their MAW score (Table 3). We found no statistically significant difference in EF; however, a significant increase in LV dimensions was observed $(p=0.002$ and $p=0.013$, respectively). A comparative analysis between groups demonstrated that even in the absence of difference in mean EF on the first study, on the second study, patients from Group B had statistically significant lower EF. We found no significant differences in LVED dimension; however, LVES dimension was significantly higher on the first and on the second 2 TTE study in patients from Group B ( $p=0.012$ and 0.050 , respectively).

Table 3: Left-ventricular parameters of the study group and in the two comparator groups

\begin{tabular}{lllll}
\hline Variable & Total & $\begin{array}{l}\text { Group A } \\
(\text { Score }<3)\end{array}$ & $\begin{array}{l}\text { Group B } \\
\text { (Score } \geq 3)\end{array}$ & $\begin{array}{l}\text { Sig (2-tailed) } \\
\text { between groups }\end{array}$ \\
\hline EF(\%) first & $51.9 \pm 8.7$ & $53.4 \pm 6.3$ & $50.9 \pm 9.8$ & $\mathrm{~ns}$ \\
EF(\%) second & $50.6 \pm 8.4$ & $51.5 \pm 7.7$ & $50.1 \pm 8.9$ & 0.051 \\
Sig. f vs. s & $\mathrm{ns}$ & 0.049 & $\mathrm{~ns}$ & \\
LVEDd $(\mathrm{mm})$ first & $51.4 \pm 5.2$ & $50.8 \pm 5.5$ & $51.8 \pm 5.0$ & $\mathrm{~ns}$ \\
LVEDd (mm) second & $53.5 \pm 5.1$ & $53.1 \pm 5.6$ & $53.7 \pm 4.9$ & $\mathrm{~ns}$ \\
Sig. f versus s & 0.002 & 0.024 & 0.033 & \\
LVEDs $(\mathrm{mm})$ first & $36.7 \pm 4.7$ & $36.2 \pm 5.0$ & $37.2 \pm 4.5$ & 0.012 \\
LVEDs (mm) second & $38.4 \pm 5.2$ & $37.9 \pm 5.2$ & $38.6 \pm 5.3$ & 0.050 \\
Sig. f versus s & 0.013 & $\mathrm{~ns}$ & $\mathrm{~ns}$ & \\
\hline EFf-EF: From the first study; EFs-EF: From the second study, LVEDdf-LVEDd: From the first study, LVEDds-
\end{tabular}

LVEDd: From the second study, LVESdf-LVESd: From the first study, LVESds-LVESd: From the second study. 
Table 4: Biochemical variables of the study group, and in the two comparator groups

\begin{tabular}{|c|c|c|c|c|c|}
\hline Variable & Total (No./\%) & Group A (Score $<3) \%$ & Group B (Score $\geq 3) \%$ & Sig. & OR $(95 \% \mathrm{Cl})$ \\
\hline \multicolumn{6}{|l|}{ Hemogram } \\
\hline $\operatorname{Er}\left(\times 10^{9}\right)$ & $4.7 \pm 0.6$ & $4.7 \pm 0.6$ & $4.8 \pm 0.6$ & ns & \\
\hline $\mathrm{Hgb}(\mathrm{g} / \mathrm{L})$ & $141.1 \pm 17.8$ & $140.4 \pm 18.7$ & $141.7 \pm 17.1$ & ns & \\
\hline Hct $(\%)$ & $41.4 \pm 4.5$ & $41.3 \pm 4.8$ & $41.4 \pm 4.4$ & ns & \\
\hline Le $(\times 109)$ & $11.3 \pm 3.5$ & $10.9 \pm 3.5$ & $11.6 \pm 3.6$ & ns & \\
\hline PLT $(\times 106)$ & $247.1 \pm 70.3$ & $256.7 \pm 85.2$ & $239.1 \pm 54.3$ & ns & \\
\hline \multicolumn{6}{|l|}{ Glycemic status } \\
\hline Stress glycemia (mmol/L) & $9.4 \pm 4.6$ & $8.3 \pm 3.7$ & $10.2 \pm 5.1$ & 0.011 & \\
\hline Stress hyperglycemia & $92(61.7)$ & $35(52.2)$ & 57 (69.5) & 0.023 & $2.1(1.1-4.1) p=0.032$ \\
\hline $\mathrm{HbA} 1 \mathrm{c}(\%)$ & $6.3 \pm 1.5$ & $6.3 \pm 1.4$ & $6.3 \pm 1.5$ & ns & \\
\hline \multicolumn{6}{|l|}{ Glico regulation } \\
\hline$>4-<10 \mathrm{mmol} / \mathrm{L}$ & $112(74.7)$ & $54(79.4)$ & $58(70.7)$ & ns & $1.6(0.7-3.4)$ \\
\hline$>10 \mathrm{mmol} / \mathrm{L}$ & $38(25.4)$ & $14(20.6)$ & $24(29.3)$ & & \\
\hline \multicolumn{6}{|l|}{ Lipoproteins } \\
\hline Cholesterol (mmol/L) & $5.7 \pm 1.3$ & $5.6 \pm 1.3$ & $5.9 \pm 1.2$ & ns & \\
\hline LDL-C (mmol/L) & $3.5 \pm 1.1$ & $3.4 \pm 1.2$ & $3.6 \pm 1.1$ & ns & \\
\hline $\mathrm{HDL}-\mathrm{C}(\mathrm{mmol} / \mathrm{L})$ & $1.2 \pm 0.3$ & $1.2 \pm 0.4$ & $1.2 \pm 0.3$ & ns & \\
\hline $\mathrm{TG}(\mathrm{mmol} / \mathrm{L})$ & $2.0 \pm 1.6$ & $1.9 \pm 1.4$ & $2.1 \pm 1.8$ & ns & \\
\hline \multicolumn{6}{|l|}{ Biochemical variables } \\
\hline BUN (mmol/L) & $6.4 \pm 3.2$ & $6.7 \pm 3.1$ & $6.1 \pm 3.3$ & ns & \\
\hline Creatinine $(\mu \mathrm{mol} / \mathrm{L})$ & $87.3 \pm 26.6$ & $91.7 \pm 27.7$ & $83.6 \pm 25.3$ & 0.050 & \\
\hline Sodium (mmol/L) & $138.3 \pm 3.4$ & $138.1 \pm 3.5$ & $138.6 \pm 3.3$ & ns & \\
\hline Potassium (mmol/L) & $4.2 \pm 0.5$ & $4.3 \pm 0.6$ & $4.1 \pm 0.5$ & 0.012 & \\
\hline Potassium $<3.5 \mathrm{mmol} / \mathrm{L}$ & $27(18.1)$ & $7(10.4)$ & $20(24.4 \%)$ & 0.012 & $2.8(1.1-7.0) ; p=0.032$ \\
\hline \multicolumn{6}{|l|}{ Cardiac biomarkers } \\
\hline hsTn (ng/L) & $9737.5 \pm 32148.5$ & $11181.2 \pm 40916.2$ & $8525.5 \pm 22509.6$ & ns & \\
\hline NTpro-BNP (pg/ml) & $3171.8 \pm 5378.7$ & $2875.2 \pm 5230.5$ & $3417.8 \pm 5504.0$ & ns & \\
\hline NTpro-BNP >125 pg/ml & $130(86.7)$ & $55(80.9)$ & $75(91.5)$ & 0.049 & $2.5(0.9-6.7) ; p=0.050$ \\
\hline
\end{tabular}

hsTn: High sensitive troponin, NTpro-BNP: N-terminal prohormone of brain natriuretic peptide:

Out of all analyzed biochemical variables, stress glycemia was significantly higher in Group B patients $(p=0.011)$, who also demonstrated worse glycemic control over the course of hospital treatment, with observed episodes of $\mathrm{Gl}>10 \mathrm{mmol} / \mathrm{L}$ (OR 1.6, $p=n s)$. Potassium level was found to be lower in Group $B(p=0.012)$, while creatinine level was higher in Group A patients $(p=0.050)$. Interestingly, patients from Group $B$ had 2.6 times higher relative risk of elevated NTproBNP levels $(p=0.060)$ (Table 4).

Variables that we found to be significantly associated with the MWA score were subjected to univariate binary logistic regression analysis to confirm significant associations. Hyperlipidemia and arterial hypertension were found to be negatively associated with MWA score 1, as were low serum potassium and creatinine levels. STEMI patients had 5.6 times higher risk to have MWA score $>3$ and Mls with multiple locations, as compared to anterior Mls (OR 2.3), while the lowest OR was found for inferior Mls (OR 0.2). Positive association with MWA score $\geq 3$ (Group B) was found for number of treated vessels. Stress glycemia was higher in Group B patients, who had 2.3 times higher risk of having unsatisfactory glycemic control. Borderline significance was detected for IVS thickness and the use of diuretics over the hospital course of treatment (Table 5).

We identified seven independently associated identifiers with a high MAW score using multivariate logistic regression analysis (backward conditional) and a model with a Chi-square test (test statistic 50.856; $p=0.000$; percent correct prediction 74.1\%). The identifiers were: STEMI, STEMI with multiple locations (excluding anterior), presence of stress hyperglycemia, creatinine and potassium, thin IVS, and treatment with diuretics during a hospital stay (Table 6).

We also analyzed correlations between MAW score and various disease variables and significant
Table 5: Variables associated with MWA score in univariate analysis

\begin{tabular}{|c|c|c|c|}
\hline Variable & beta & $\begin{array}{l}\text { ExpB }(95 \% \text { Cl) / Mantel- } \\
\text { Haenszel OR }\end{array}$ & Sig. \\
\hline HLP & -0.178 & $1.121(1.020-1.232) p=0.038$ & 0.021 \\
\hline HTA & -0.179 & $1.118(1.001-1.250) p=0.065$ & 0.046 \\
\hline STEMI & 1.736 & $5.676(1.448-22.247) p=0.013$ & 0.000 \\
\hline $\begin{array}{l}\text { ST-seg elevation } \\
\text { MI location }\end{array}$ & 0.404 & & 0.000 \\
\hline $\begin{array}{l}\text { Multiple versus anterior } \\
\text { Inferior versus anterior }\end{array}$ & $\begin{array}{l}0.834 \\
-1.367\end{array}$ & $\begin{array}{l}2.303(0.957-5.544) p=0.063 \\
0.255(0.098-0.661) p=0.005\end{array}$ & 0.019 \\
\hline NO of treated vessels & 0.283 & & 0.000 \\
\hline NTpro-BNP >125pg/ml & 0.929 & OR $2.532(0.961-6.765) p=0.064$ & 0.080 \\
\hline Stress hyperglycemia (mmol/L) & .158 & & 0.054 \\
\hline Glico-regulation & 0.777 & $2.174(1.087-4.348) p=0.028$ & 0.026 \\
\hline WBC $\left(\times 10^{6}\right)$ & 0.147 & & 0.063 \\
\hline Creatinine $(\mu \mathrm{mol} / \mathrm{L})$ & 0.165 & & 0.043 \\
\hline Potassium (mmol/L) & -0.209 & & 0.010 \\
\hline IVS (mm) & -0.271 & & 0.001 \\
\hline Diuretics treatment & 0.591 & $1.806(0.926-3.523) p=0.083$ & 0.070 \\
\hline
\end{tabular}

correlation coefficients are displayed in Table 7 and Figure 2.

Predictive functions of various biochemical variables (hsTn, NTpro-BNP, stress glycemia, WBC, creatinine, and potassium) were subjected to ROC curve analysis (Figure 3 with accompanying table). Only two biochemical variables demonstrated statistically significant discriminatory function for MWA score $(\geq 3)$ : High-stress glycemia and low serum potassium (area under the curve .618 , and $.371, p=0.013$ and 0.007 , respectively).

\section{Discussion}

We investigated the predictive value of the MAW score of acuteness as compared with biochemical, LV functional parameters, extent and severity of CAD, and in-hospital clinical outcome. Our general finding is a high degree of agreement between MAW score and biochemical variables, as measured in the acute phase of MI. 
Electrocardiography (ECG), since its invention, is the main diagnostic tool for Ml diagnosis, in the same time localizing the site of infarction, with different leads representing the specific myocardial areas [19]. The evolution of Ml begins early after an acute coronary artery occlusion and the subsequent ECG changes are caused by the development of ischemia and later on necrosis. Initial ECG changes - tall T-waves are very often undetected, as they develop within minutes after acute occlusion. They are followed by the evolvement of ST-segment elevation, abnormal Q waves, T-wave inversion, and lastly, resolution of the ST-segment elevation [14].

Table 6: Multivariate logistic regression analysis

\begin{tabular}{|c|c|c|c|c|c|c|}
\hline \multirow[t]{2}{*}{ Variables } & \multirow[t]{2}{*}{ B } & \multirow[t]{2}{*}{ Wald } & \multirow[t]{2}{*}{ Sig. } & \multirow[t]{2}{*}{$\operatorname{Exp}(B)$} & \multicolumn{2}{|c|}{$95 \% \mathrm{Cl}$ for $\operatorname{EXP}(\mathrm{B})$} \\
\hline & & & & & Lower & Upper \\
\hline STEMI/NSTEMI & -1.194 & 4.514 & $0.034^{*}$ & 0.303 & 0.101 & 0.912 \\
\hline $\begin{array}{l}\text { MI location } \\
\text { (multiple versus) }\end{array}$ & & 4.906 & 0.086 & & & \\
\hline $\mathrm{Ml}$ anterior & -0.987 & 2.821 & 0.093 & 0.373 & 0.118 & 1.179 \\
\hline MI inferior & -1.305 & 4.733 & $0.030^{\star}$ & 0.271 & 0.084 & 0.879 \\
\hline Number of treated CA & 1.316 & 2.526 & 0.112 & 3.727 & 0.736 & 18.882 \\
\hline $\begin{array}{l}\text { Stress hyperglycemia } \\
(\mathrm{mmol} / \mathrm{L})\end{array}$ & 0.111 & 4.131 & $0.042^{*}$ & 1.118 & 1.004 & 1.245 \\
\hline Creatinine $(\mu \mathrm{mol} / \mathrm{L})$ & -0.017 & 3.905 & $0.048^{*}$ & 0.983 & 0.966 & 1.000 \\
\hline Potassium (mmol/L) & -1.357 & 6.076 & $0.014^{*}$ & 0.257 & 0.087 & 0.757 \\
\hline IVS (mm) & -0.308 & 5.423 & $0.020^{*}$ & 0.735 & 0.567 & 0.952 \\
\hline Diuretics treatment & 1.212 & 6.093 & $0.014^{*}$ & 3.360 & 1.283 & 8.798 \\
\hline Constant & 11.735 & 12.305 & 0.000 & 124844.073 & & \\
\hline
\end{tabular}

infarction, MI: Myocardial infarction, IVS: Interventricular septum.

The original Anderson-Wilkins acuteness score was developed for MI with anterior localization and could not be used when inferior MI was present [12]. The problem is the abnormal Q-wave criterion ( $\geq 30 \mathrm{~ms}$ duration), that is rarely met in the inferior leads, where predominantly positive QRS complex is expected [13]. The MAW score loosens up the strict criteria and adjusts the Q-wave criterion from $\geq 30 \mathrm{~ms}$ to $\geq 20 \mathrm{~ms}$ in inferior leads, and thus the MAW score predicts myocardial salvage equally well for anterior and inferior AMI [8], [13], (Table 8).

Table 7: Significant correlations with MAW score

\begin{tabular}{lll}
\hline Variable & Correlation $(r)$ & Sig $(p)$ \\
\hline Length of hospitalization & 0.157 & 0.056 \\
HLP & -0.178 & 0.029 \\
HTA & -0.201 & 0.014 \\
Type of MI (STEMI) & $-0.413^{\star *}$ & 0.000 \\
ST-seg. elevation & $0.423^{\star *}$ & 0.000 \\
NO of treated CA & $0.276^{\star *}$ & 0.000 \\
Stress glycemia & 0.169 & 0.039 \\
WBC & 0.166 & 0.042 \\
Potassium (low) & -0.206 & 0.012 \\
IVS (thin) & $-0.305^{\star *}$ & 0.000 \\
\hline
\end{tabular}

IVS (thin) 0.000 WBC: White blood, MAW: Modified Anderson-Wilkins

\begin{tabular}{llllll}
\hline Test result variable(s) & Area & Std. Error & $\begin{array}{l}\text { Asymptotic } \\
\text { Sig }\end{array}$ & \multicolumn{2}{c}{ Asymptotic 95\% Cl } \\
\cline { 5 - 6 } & & & Lower bound & Upper bound \\
\hline hsTn $(\mathrm{ng} / \mathrm{L})$ & 0.474 & 0.048 & 0.583 & 0.380 & 0.567 \\
NTpro-BNP $(\mathrm{pg} / \mathrm{ml})$ & 0.561 & 0.048 & 0.203 & 0.467 & 0.654 \\
Stress Gl $(\mathrm{mmol} / \mathrm{L})$ & 0.618 & 0.046 & $0.013^{*}$ & 0.528 & 0.709 \\
WBC $\left(\times 10^{9}\right)$ & 0.567 & 0.047 & 0.160 & 0.474 & 0.660 \\
Creatinine $(\mu$ mole/L) & 0.410 & 0.047 & 0.060 & 0.318 & 0.503 \\
Potassium (mmol/L) & 0.371 & 0.046 & $0.007^{\star}$ & 0.281 & 0.460 \\
\hline hsTn: High-sensitive troponin, NTpro-BNP: N-terminal prohormone of brain natriuretic peptide, WBC: White
\end{tabular}
blood cells.

According to the first study addressing the prognostic value of the MAW acuteness score, when stratifying patients by MAW acuteness score, the initial difference in myocardial salvage results in a long-term difference in mortality, while the incidence of re-infarction is independent of the MAW score [10].
Table 8: Lead specific criteria for abnormal Q-waves and tall T-waves

\begin{tabular}{lll}
\hline Lead & Abnormal Q-wave & Tall T-wave \\
\hline I & $\geq 30 \mathrm{~ms}$ & $\geq 0.50 \mathrm{mV}$ \\
II & $\geq 30 \mathrm{~ms}$ & $\geq 0.50 \mathrm{mV}$ \\
III & $\geq 30 \mathrm{~ms}$ and abnormal Q in aVF & $\geq 0.25 \mathrm{mV}$ \\
aVR & - & - \\
aVL & $\geq 30 \mathrm{~ms}$ & $\geq 0.25 \mathrm{mV}$ \\
aVF & $\geq 30 \mathrm{~ms}$ & $\geq 0.50 \mathrm{mV}$ \\
V1 & Any Q-wave & $\geq 0.50 \mathrm{mV}$ \\
V2 & Any Q-wave & $\geq 1.0 \mathrm{mV}$ \\
V3 & Any Q-wave & $\geq 1.0 \mathrm{mV}$ \\
V4 & $\geq 30 \mathrm{~ms}$ & $\geq 1.0 \mathrm{mV}$ \\
V5 & $\geq 30 \mathrm{~ms}$ & $\geq 0.75 \mathrm{mV}$ \\
V6 & $\geq 30 \mathrm{~ms}$ & $\geq 0.50 \mathrm{mV}$ \\
\hline Ms: Milliseconds, mV: Millivolts. &
\end{tabular}

\section{Association of common comorbidities and risk factors for AMI and MAW score}

Our data showed that hyperlipidemia and arterial hypertension were more frequent in patients with MAW score $<3$ (less acute and less severe).

Arterial hypertension is a well-known major risk factor for CAD and MI [20]. Over $90 \%$ of MI victims bear many risk factors for coronary atherosclerosis besides HTN, smoking habit, obesity, dyslipidemia, etc. HTN is an independent risk factor over other risk factors that may coexist. There is a linear increase in the risk of MI with an increase of blood pressure. HTN particularly raises the risk of $\mathrm{Ml}$ in people under 65 years [21]. Along with HTA, the other major risk factor for CVD is hyperlipidemia or dyslipidemia [22], [23], [24], [25]. According to Ballarino et al., age, gender, receiving therapy for CVD, smoking, hypertension, hypercholesterolemia, and increased BMI are all predictive of the acute coronary syndrome [26]. In the FAST MI registry, patients with $Q$ wave tend to be younger, males, with a history of smoking and family history. Patients with non-Q wave Mls were heavily burdened with risk factors and had worse baseline demographic characteristics [37].

This might be the explanation why in our study population, patients with lower acuteness severity index were more often patients with hypertension and hyperlipidemia.

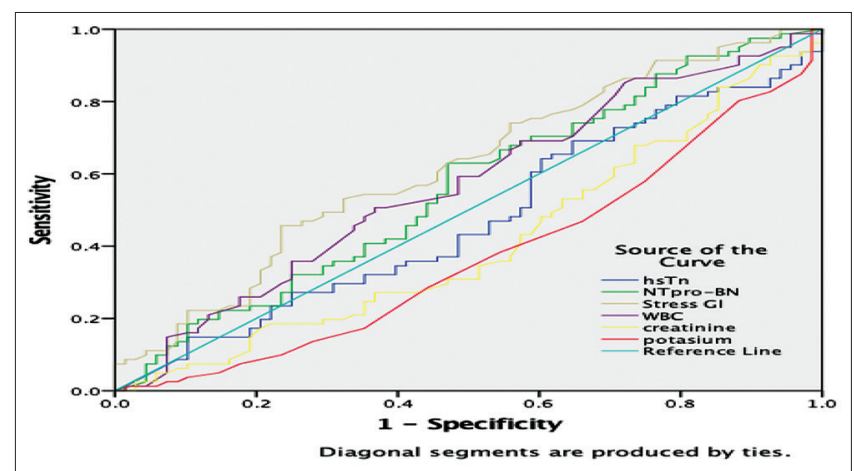

Figure 3: Receiver operating characteristic curve for modified Anderson-Wilkins score and biochemical variables

Association of biochemical variables with 


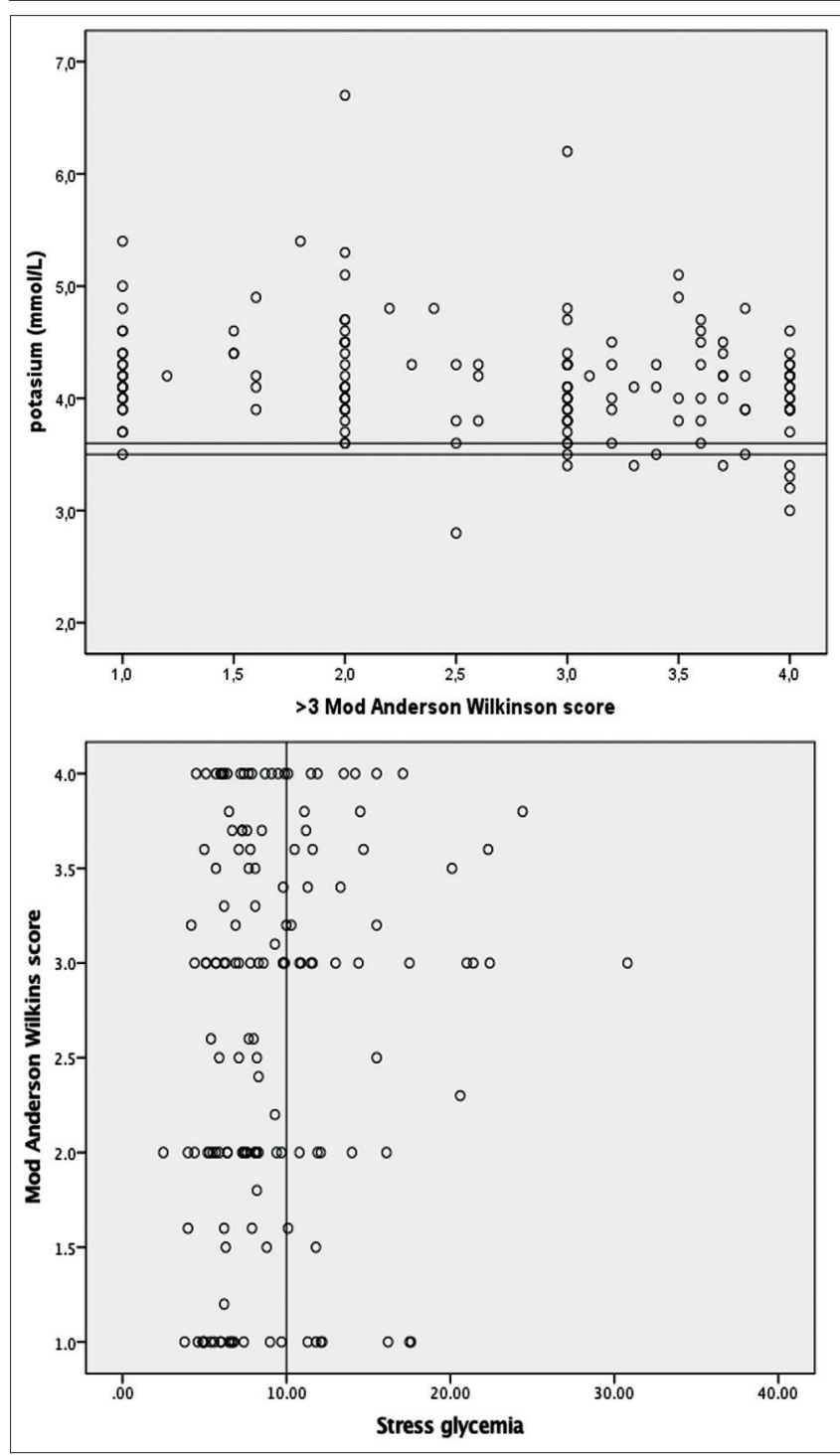

Figure 2: Correlation coefficient matrix of modified Anderson-Wilkins score with potassium and stress glycemia

\section{MAW}

We found that stress hyperglycemia, serum levels of potassium, and creatinine are statistically significant associated with the MAW score of acuteness, as well as natriuretic peptide (NT-proBNP).

According to the definition of The American Diabetes Association, stress hyperglycemia is an elevation of fasting glucose $\geq 7 \mathrm{mmol} / \mathrm{L}$, or $2-\mathrm{h}$ postprandial glucose $\geq 11 \mathrm{mmol} / \mathrm{L}$, in a patient without previous diabetes mellitus. Distinction on whether a patient has stress glycemia or previously undiagnosed diabetes is made by glycated hemoglobin (HbA1c). HbA1c value $\geq 6.5 \%$ indicates preexisting unrecognized diabetes, while value $\leq 6.5 \%$ indicates stress hyperglycemia [27]. Studies show that stress hyperglycemia is present in one of four hospitalized ACS patients, and it is found in $41 \%$ of elderly patients. Stress hyperglycemia can be used as a prognostic indicator in patients with AMI [28], [29] According to Marfella et al. [30], patients with hyperglycemia had a larger infarct size compared with normoglycemic patients, and also, there is evidence that supports an association between ventricular desynchrony and blood glucose levels in patients with $\mathrm{MI}$, and an association with early in-hospital mortality in patients with AMI [31].

Our data is in concordance with such findings. In our study, patients from Group B had OR of 2.1 ( $p=0.023$ ) of having stress hyperglycemia, which also demonstrated a very good discriminatory function as a continuous variable with ROC analysis (area under the curve .618, $p=0.013$ ).

Normal serum potassium level ranges from 3.5 to $5.1 \mathrm{mmol} / \mathrm{L}$ in adults [32], while low potassium level is described in approximately $8 \%$ of patients with $\mathrm{MI}$ [33]. According to Goyal et al., a higher mortality rate can be observed in AMI patients with potassium levels below 3.5 and above $4.5 \mathrm{mmol} / \mathrm{L}$. The "so-called" safe window is levels $3.5-4.5 \mathrm{mmol} / \mathrm{L}$ [34].

In our study, we found that serum potassium was statistically significantly lower in Group $B(p=0.012)$, with an OR of $2.8(p=0.032)$, as compared to Group A, to have serum potassium $<3.5 \mathrm{mmol} / \mathrm{L}$. No significant association with in-hospital morbidity was observed.

Renal dysfunction is a strong independent predictor of cardiovascular outcome after MI [35]. Cakar et al. found that the presence of elevated creatinine on admission in STEMI patients is associated with increased 1-year mortality, independent of other conventional risk factors [36].

We found that patients from Group A had higher serum creatinine level ( $p=0.048)$, which is in accordance with the literature, as patients with renal dysfunction tend more often to be late presenters.

Natriuretic peptides are not only biomarkers for the diagnosis of heart failure but even more important prognostic markers. In Ml patients, natriuretic peptides correlate with the presence and degree of heart failure in the early phase, but also, they are powerful prognosticators of LV remodeling, LV dysfunction, and early and late cardiac morbidity and mortality. Fakhri et al. demonstrated the association of MAW score with increasing NT-proBNP levels. In STEMI patients with severe ischemia, neurohormonal activation is inversely associated with ECG patterns of acute myocardial ischemia [38].

We found high levels of natriuretic peptides (NT-proBNP was measured), without inter-group statistically significant difference. However, patients from Group B had OR 2.5 ( $p=0.050)$, to have NT-proBNP level above $125 \mathrm{pg} / \mathrm{ml}$.

\section{LV functional parameters and MAW score}

LVEF is one of the well-known predictors of prognosis in patients with $\mathrm{AMI}$, the lower the EF, the worse the mortality and morbidity will be [16]. The SAVE echocardiography substudy reported that larger infarct size 
correlates with LV shape distortion and predicts progressive LV dilatation, LV dysfunction, and cardiac death [16], [18].

Simple comparative statistics of LV morphological and functional parameters measured with 2-D TTE on the first and second measurements found no statistically significant differences between the two groups. However, paired sample statistics revealed a completely different situation when comparing LV morphology after the 3 months period. This is a period of LV remodeling after $\mathrm{MI}$, and we observed that there was no significant change in global LV function as measured through EF (\%). However, signs of LV remodeling can be observed through statistically significant increases of LV dimensions (end-diastolic and end-systolic, $p=0.002$ and $p=0.013$, respectively) that were taken as surrogate markers for LV volumes. That said, comparing the process of $L V$ remodeling in the patients from the two groups, we observed a statistically significant decrease of EF on the follow-up study in Group B patients, while patients from both groups had increased LVES dimensions. It is our conclusion that, even in such a small study population, a more pronounced LV remodeling can be predicted with a more severe MAW score of acuteness.

Fakhri et al. used global longitudinal strain analysis (GLS) and reported that pre-hospital risk stratification by ECG identifies patients with acute and severe ischemia who are at increased risk for reduced ventricular function (assessed by GLS) after STEMI. Optimizing reperfusion delays in these patients can, therefore, be of particular benefit in improving clinical outcome after STEMI [4].

\section{Limitations}

One of the biggest limitations of this study is the number of study subjects, bearing in mind the prevalence of the disease, which may, in some way, affect the results that we received.

Furthermore, another limitation of the study is that we only applied 2-D TTE early and after 3 months of $\mathrm{MI}$, no imaging modality that can distinct myocardium at risk and final area of necrosis was applied.

However, this is the first study done with an analysis of NTpro-BNP in a cohort of patients with acute $\mathrm{Ml}$ for prognostication purposes. Even though this is a biomarker known for several years, it was not widely available in our country, and to our knowledge, this is the first study that analyzes the role of natriuretic peptides in the prognostication of MI patients.

\section{Conclusion}

ECG is still an irreplaceable tool in diagnosis and prognosis of $\mathrm{Ml}$ patients. ECG-derived scores, as
MAW score, are better surrogate markers of "times" in MI patients. MAW score demonstrates a strong correlation with biochemical variables: Stress hyperglycemia, serum potassium and creatinine level, and natriuretic peptides. MAW score can serve as an early marker of LV remodeling, as demonstrated by the correlation with LV parameters.

However, we were unable to demonstrate a significant association of MAW score with in-hospital morbidity nor mortality. Larger scale studies are needed to draw such conclusions.

\section{Acknowledgment}

We would like to acknowledge the collaboration and support of the colleges and nurses in the ICCU at the University Clinic for Cardiology for their help and support over the course of this study that is a part of broader work on my doctoral thesis.

\section{References}

1. Ioacara S, Popescu AC, Tenenbaum J, Dimulescu DR, Popescu MR, Sirbu A, et al. Acute myocardial infarction mortality rates and trends in Romania between 1994 and 2017. Int J Environ Res Public Health. 2019;17(1):285. https://doi. org/10.3390/ijerph17010285

PMid:31906114

2. Denktas AE, Anderson HV, McCarthy J, Smalling RW. Total ischemic time: The correct focus of attention for optimal ST-segment elevation myocardial infarction care. JACC Cardiovasc Interv. 2011;4(6):599-604. https://doi.org/10.1016/j. jcin.2011.02.012

PMid:21700244

3. Floyd JS, Maynard C, Weston P, Johanson P, Jennings RB, Wagner GS. Effects of ischemic preconditioning and arterial collateral flow on ST-segment elevation and QRS complex prolongation in a canine model of acute coronary occlusion. $J$ Electrocardiol. 2009;42:19-26. https://doi.org/10.1016/j. jelectrocard.2008.09.006

PMid:19070706

4. Fakhri $\mathrm{Y}$, Ersbøll M, Køber L, Hassager C, Hesselfeldt $\mathrm{R}$, Steinmetz J, et al. Pre-hospital electrocardiographic severity and acuteness scores predict left ventricular function in patients with ST elevation myocardial infarction. J Electrocardiol. 2016;49(3):284-91. https://doi.org/10.1016/j. jelectrocard.2016.02.012

PMid:26962019

5. Lønborg J, Schoos MM, Kelbæk H, Holmvang L, Steinmetz J, Vejlstrup $\mathrm{N}$, et al. Impact of system delay on infarct size, myocardial salvage index, and left ventricular function in patients with ST-segment elevation myocardial infarction. Am Heart J. 2012;164(4):538-46. https://doi.org/10.1016/j.ahj.2012.07.021 PMid:23067912

6. Steg PG, James SK, Atar D, Badano LP, Blömstrom-Lundqvist C Borger MA, et al. ESC Guidelines for the management of acute myocardial infarction in patients presenting with ST-segment 
elevation. Eur Heart J. 2012;33(20):2569-619.

PMid:22922416

7. Terkelsen CJ, Sørensen JT, Maeng M, Jensen LO, Tilsted HH, Trautner S, et al. System delay and mortality among patients with STEMI treated with primary percutaneous coronary intervention. JAMA. 2010;304(7):763-71. https://doi. org/10.1001/jama.2010.1139

PMid:20716739

8. Corey KE, Maynard C, Pahlm O, Wilkins ML, Anderson ST, Cerqueira MD, et al. Combined historical and electrocardiographic timing of acute anterior and inferior myocardial infarcts for prediction of reperfusion achievable size limitation. Am J Cardiol. 1999;83(6):826-31. https://doi. org/10.1016/s0002-9149(98)01042-x

PMid:10190393

9. Engblom H, Strauss DG, Heden B, Hedström E, Jovinge S, Gotberg $M$, et al. The evaluation of an electrocardiographic myocardial ischemia acuteness score to predict the amount of myocardial salvage achieved by early percutaneous coronary intervention clinical validation with myocardial perfusion single photon emission computed tomography and cardiac magnetic resonance. J Electrocardiol. 2011;44(5):525-32. https://doi. org/10.1016/j.jelectrocard.2011.03.008

PMid:21658711

10. Sejersten M, Ripa RS, Maynard C, Grande P, Andersen HR, Wagner GS, et al. Timing of ischemic onset estimated from the electrocardiogram is better than historical timing for predicting outcome after reperfusion therapy for acute anterior myocardial infarction: A DANish trial in acute myocardial infarction 2 (DANAMI-2) substudy. Am Heart J. 2007;154(1):61. https://doi. org/10.1016/j.ahj.2007.04.003

PMid: 17584552

11. Fakhri $Y$, Schoos MM, Clemmensen $P$, Sejersten M. Clinical use of the combined Sclarovsky Birnbaum Severity and Anderson Wilkins acuteness scores from the pre-hospital ECG in ST-segment elevation myocardial infarction. J Electrocardiol. 2014;47(4):566-70. https://doi.org/10.1016/j. jelectrocard.2014.03.009

PMid:24792905

12. Wilkins ML, Pryor AD, Maynard C, Wagner NB, Elias WJ, Litwin PE, et al. An electrocardiographic acuteness score for quantifying the timing of a myocardial infarction to guide decisions regarding reperfusion therapy. Am J Cardiol. 1995;75(8):61720. https://doi.org/10.1016/s0002-9149(99)80629-8

PMid:7887390

13. Hedén B, Ripa R, Persson E, Song Q, Maynard C, Leibrandt P, et al. A modified Anderson-Wilkins electrocardiographic acuteness score for anterior or inferior myocardial infarction. Am Heart J. 2003;146(5):797-803. https://doi.org/10.1016/ s0002-8703(03)00404-6

PMid:14597927

14. Fakhri $Y$, Sejersten M, Schoos MM, Hansen HS, DuboisRande JL, Hall TS, et al. Electrocardiographic scores of severity and acuteness of myocardial ischemia predict myocardial salvage in patients with anterior ST-segment elevation myocardial infarction. J Electrocardiol. 2017;51(2):195-202. https://doi.org/10.1016/j.jelectrocard.2017.12.010

PMid:29174706

15. Esmaeilzadeh $M$, Parsaee $M$, Maleki $M$. The role of echocardiography in coronary artery disease and acute myocardial infarction. J Tehran Heart Cent. 2013;8(1):1-13. PMid:23646042

16. Sia YT, O'Meara E, Ducharme A. Role of echocardiography in acute myocardial infarction. Curr Heart Fail Rep. 2008;5(4):18996. https://doi.org/10.1007/s11897-008-0029-6
PMid: 19032913

17. White HD, Norris RM, Brown MA, Brandt PW, Whitlock RM, Wild CJ. Left ventricular end-systolic volume as the major determinant of survival after recovery from myocardial infarction. Circulation. 1987;76(1):44-51. https://doi.org/10.1161/01. cir.76.1.44

\section{PMid:3594774}

18. Møller JE, Hillis GS, Oh JK, Reeder GS, Gersh BJ, Pellikka PA Wall motion score index and ejection fraction for risk stratification after acute myocardial infarction. Am Heart J. 2006;151(2):41925. https://doi.org/10.1016/j.ahj.2005.03.042 PMid: 16442909

19. Gupta D, Agrawal P, Nohria S, Singh A. To study the correlation of location of myocardial infarction according to ECG and echocardiography. IOSR J Dent Med Sci. 2015;14(8):12-5.

20. Pandit A. Hypertension and myocardial infarction: A study and review. J Cardiol Clin Res. 2017;5(6):1118-23.

21. Pedrinelli R, Ballo P, Fiorentini C, Denti S, Galderisi M, Ganau A, et al. Hypertension and acute myocardial infarction: An overview. J Cardiovasc Med. 2012;13(3):194-202. https:// doi.org/10.2459/jcm.0b013e3283511ee2

PMid:22317927

22. Konstantinou K, Tsioufis C, Koumelli A, Mantzouranis M, Kasiakogias A, Doumas M, et al. Hypertension and patients with acute coronary syndrome: Putting blood pressure levels into perspective. J Clin Hypertens (Greenwich). 2019;21(8):113543. https://doi.org/10.1111/jch.13622

PMid:31301119

23. Mach F, Baigent C, Catapano AL, Koskinas KC, Casula M, Badimon L, et al. 2019 ESC/EAS Guidelines for the management of dyslipidaemias: Lipid modification to reduce cardiovascular risk. Eur Heart J. 2020;41(1):111-88. https://doi. org/10.15829/1560-4071-2020-3826

PMid:31504418

24. Klimchak AC, Patel MY, lorga ŞR, Kulkarni N, Wong ND. Lipid treatment and goal attainment characteristics among persons with atherosclerotic cardiovascular disease in the United States. Am J Prev Cardiol. 2020;1:100010. https://doi.org/10.1016/j. ajpc.2020.100010

25. Ballarino $P$, Cervellin G, Trucchi C, Altomonte F, Bertini A Bonfanti L, et al. An Italian registry of chest pain patients in the emergency department: Clinical predictors of acute coronary syndrome. Minerva Med. 2020;111(2):120-32. https://doi. org/10.23736/s0026-4806.20.06472-1 PMid:32338841

26. Backer GD, Jankowski P, Kotseva K, Mirrakhimov E, Reiner Ž, Rydén $\mathrm{L}$, et al. Management of dyslipidaemia in patients with coronary heart disease: Results from the ESC-EORP EUROASPIRE $V$ survey in 27 countries. Atherosclerosis. 2019;285:135-46.

PMid:31054483

27. Vavlukis M, Zafirovska B, Antova E, Pocesta B, Shehu E, Taravari $\mathrm{H}$, et al. The impact of glyco-metabolic status in patients treated for acute coronary syndrome. Pril (Makedon Akad Nauk Umet Odd Med Nauki). 2018;39(1):37-50. https:// doi.org/10.2478/prilozi-2018-0022 PMid:30110257

28. Kurt NG, Orak M, Ustundag M. Relation between stress hyperglycemia and mortality in patients with acute myocardial infarction. Eurasian J Med Oncol. 2018;2(3):138-41.

29. Sanjuán R, Núñez J, Blasco ML, Miñanab G, MartínezMaicasa $\mathrm{H}$, Carbonell $\mathrm{N}$, et al. Prognostic implications of stress hyperglycemia in acute ST elevation myocardial infarction. Prospective observational study. Rev Esp Cardiol. 2011;64(3):201-7. https://doi.org/10.1016/j.rec.2010.08.005 


\section{PMid:21330037}

30. Marfella R, Siniscalchi M, Esposito K, Sellitto A, De Fanis U, Romano $\mathrm{C}$, et al. Effects of stress hyperglycemia on acute myocardial infarction: Role of inflammatory immune process in functional cardiac outcome. Diabetes Care. 2003;26(11):312935. https://doi.org/10.2337/diacare.26.11.3129

31. Cinar H, Avci A, Gulen M, Avci BS, Comertpay E, Satar S. Does stress hyperglycemia affect mortality? Acute myocardial infarction-case control study. Arch Med Sci Atheroscler Dis. 2019;4(1):e201-7. https://doi.org/10.5114/amsad.2019.87303

$$
\text { PMid:31538125 }
$$

32. Dixon DL, Abbate A. Potassium levels in acute myocardial infarction: Definitely worth paying attention to. Eur Heart J Cardiovasc Pharmacother. 2015;1(4):252-3. https://doi. org/10.1093/ehjcvp/pvv029

PMid:27532448

33. Madias JE, Shah B, Chintalapally G, Chalavarya G, Madias NE. Admission serum potassium in patients with acute myocardial infarction: Its correlates and value as a determinant of in-hospital outcome. Chest. 2000;118(4):904-13. https://doi.org/10.1378/ chest.118.4.904

PMid:11035655

34. Goyal A, Spertus JA, Gosch K, Venkitachalam L, Jones PG, Van den Berghe $\mathrm{G}$, et al. Serum potassium levels and mortality in acute myocardial infarction. JAMA. 2012;307(2):157-64. https:// doi.org/10.1001/jama.2011.1967

\section{PMid:22235086}

35. Jose P, Skali H, Anavekar N, Tomson C, Krumholz HM, Rouleau JL, et al. Increase in creatinine and cardiovascular risk in patients with systolic dysfunction after myocardial infarction. $J$ Am Soc Nephrol. 2006;17(10):2886-91. https://doi.org/10.1681/ asn.2006010063

PMid: 16928807

36. Cakar MA, Gunduz H, Vatan MB, Kocayigit I, Akdemir R. The effect of admission creatinine levels on one-year mortality in acute myocardial infarction. Sci World J. 2012;2012:186495. https://doi.org/10.1100/2012/186495

PMid:22619619

37. Cambou JP, Simon T, Mulak G, Bataille V, Danchin N. The French registry of acute ST elevation or non-ST-elevation myocardial Infarction (FAST-MI): Study design and baseline characteristics. Arch Mal Coeur Vaiss. 2007;100(6-7):524-34. https://doi.org/10.1136/heartjnl-2012-301700

PMid:17893635

38. Fakhri $\mathrm{Y}$, Schoos MM, Sejersten M, Ersbøll M, Valeur $N$, Køber $L$, et al. Prehospital electrocardiographic acuteness score of ischemia is inversely associated with neurohormonal activation in STEMI patients with severe ischemia. J Electrocardiol. 2017;50(1):90-6. https://doi.org/10.1016/j. jelectrocard.2016.11.002

PMid:27887720 